\title{
Content overview
}

About the author

Preface and acknowledgments xvi

List of abbreviations xix

Table of legal sources xxiii

1 Introduction to Anti-Money Laundering Regulation and Compliance

2 Introductory overview of money laundering and terrorist financing risks and their regulation

$3 \mathrm{AML} / \mathrm{CFT}$ and OFAC regulatory, supervisory, and enforcement framework

$4 \quad \mathrm{AML} / \mathrm{CFT}$ and OFAC reporting, recordkeeping, and information sharing requirements

5 Regulatory expectations for AML/CFT and sanctions compliance programs

6 The role of corporate governance in mitigating AML/ CFT and sanctions compliance risk

7 The role of risk management in meeting AML/CFT and OFAC regulatory expectations

8 The risk-based approach to suspicious transaction monitoring and sanctions screening

Appendix 239

References 249

Index 253 